\title{
INIQUIDADES DE GÊNERO E VULNERABILIDADE ÀS IST/HIVIAIDS EM ADOLESCENTES DE ASSENTAMENTO URBANO: UM ESTUDO EXPLORATÓRIO
}

\author{
GENDER INEQUALITIES AND VULNERABILITY TO STI/HIV/AIDS IN \\ URBAN SETTLEMENT ADOLESCENTS: AN EXPLORATORY STUDY
}

\section{INIQUIDADES DE GÉNERO Y VULNERABILIDAD A LAS ITS/VIH/SIDA EN ADOLESCENTES DE ASENTAMIENTO URBANO: UN ESTUDIO EXPLORATORIO}

\author{
Sara Oliveira Souza* \\ Andressa Cunha De Paula** \\ Carla De Almeida Silva ${ }^{* * *}$ \\ Paulie Marcelly Ribeiro Dos Santos Carvalho**** \\ Marcia Maria De SouZa***** \\ Marcos Matos Matos******
}

\section{RESUMO}

Objetivo: Compreender a percepção acerca da vulnerabilidade às IST/HIV/AIDS entre as adolescentes residentes em assentamento urbano de uma capital do Brasil Central. Material e Método: Estudo descritivo e exploratório, com abordagem qualitativo, realizado em assentamento da periferia de uma capital do Brasil Central. De um total de 407 adolescentes da única instituição do assentamento, 107 foram considerados para o estúdio, 20 deles assistiram à consulta hebiátrica até atingir a saturação dos dados, a amostra final foi constituída por 16 adolescentes. Os dados foram obtidos por meio de entrevistas semiestruturadas. A análise de conteúdo foi utilizada para tratar os dados, sob a ótima da Teoria das Representaçóes Sociais. Resultados: Emergiram

\footnotetext{
*Mestranda em Cuidado em Enfermagem, Faculdade de Enfermagem, Universidade Federal de Goiás, Goiânia, GO, Brasil. ORCID: https://orcid.org/0000-0003-0066-036X, E-mail: sara_osouza@hotmail.com

** Mestranda em Cuidado em Enfermagem, Faculdade de Enfermagem, Universidade Federal de Goiás, Goiânia, GO, Brasil. ORCID: https://orcid.org/0000-0002-9728-135X, E-mail: dessapaula@hotmail.com

***Mestranda em Cuidado em Enfermagem, Faculdade de Enfermagem, Universidade Federal de Goiás, Goiânia, GO, Brasil. ORCID: https://orcid.org/0000-0002-7225-6502, E-mail: carla-biomed@hotmail.com

**** Doutoranda em Cuidado em Enfermagem, Faculdade de Enfermagem, Universidade Federal de Goiás, Goiânia, GO, Brasil. ORCID: https://orcid.org/0000-0003-0056-364X, E-mail: pauliemarcelly@gmail.com

*****Dra. em Ciências da Saúde. Faculdade de Enfermagem, Universidade Federal de Goiás, Goiânia, GO, Brasil. ORCID: https://orcid.org/0000-0003-1467-3866, Email: marcia.fen@gmail.com

******Dr. em Ciências da Saúde, Faculdade de Enfermagem, Universidade Federal de Goiás, Goiânia, GO, Brasil. ORCID: https://orcid.org/0000-0001-8643-7032,E-mail: marcosmatos@ufg.br Autor correspondente
} 
as seguintes categorias temáticas: sentimento de invulnerabilidade às IST/HIV/AIDS; relação de gênero e vulnerabilidade às IST/HIV/AIDS e sexualidade, rede social e vulnerabilidade às IST/HIV/AIDS. Conclusão: As adolescentes assentadas são marcadas pela subalternidade de gênero, que muitas vezes é negada e naturalizada pelos ideais de legitimaçáo de desigualdade entre os sexos.

Palavras-chave: Iniquidade de Gênero; Saúde do Adolescente; Vulnerabilidade; Síndrome de Imunodeficiência Adquirida; Infecções Sexualmente Transmissíveis.

\begin{abstract}
Objective: To understand the perception about the vulnerability to STI/HIV/AIDS among female adolescents living in an urban settlement in a city of Central Brazil. Materials and Methods: Descriptive and exploratory study, with qualitative approach, carried out in an urban settlement on the outskirts of a capital city in central Brazil. From a population of 407 adolescents from the only educational institution in the settlement, 107 were considered for the study. Of these, 20 went for hebiatric consultation and, until data saturation was reached, the final sample consisted of 16 adolescents. Data were obtained through semi-structured interviews. Content analysis was used to treat the data from the perspective of the Theory of Social Representations. Results: The following thematic categories emerged: feeling of invulnerability to STI/HIV/AIDS; gender relationship and vulnerability to STI/HIV/AIDS and sexuality, social network and vulnerability to STI/HIV/AIDS. Conclusion: Adolescent girls from the settlement are marked by gender subordination, which is often denied by them and naturalized by the ideals of legitimizing gender inequality.
\end{abstract}

Key words: Gender Inequality; Adolescent Health; Vulnerability; Acquired Immunodeficiency Syndrome; Sexually Transmitted Infections.

\title{
RESUMEN
}

Objetivo: Comprender la percepción sobre la vulnerabilidad a las IST/VIH/SIDA entre las adolescentes que viven en un asentamiento urbano en una capital del centro de Brasil. Material y Método: Estudio descriptivo y exploratorio, de abordaje cualitativo, realizado en un asentamiento urbano de la periferia de una capital de Brasil central. De un total de 407 adolescentes de la única institución del asentamiento, 107 fueron considerados para el estudio, de ellos, 20 acudieron a consulta hebiátrica y hasta que se alcanzó la saturación de datos, la muestra final quedó constituida por 16 adolescentes. Los datos se obtuvieron a través de entrevistas semiestructuradas. El análisis de contenido se utilizó para tratar los datos, bajo el óptimo de la Teoría de las representaciones sociales. Resultados: Surgieron las siguientes categorías temáticas: sensación de invulnerabilidad a las IST/VIH/ SIDA; Relación de género y vulnerabilidad a las IST/VIH/SIDA y Sexualidad, red social y vulnerabilidad a las IST/VIH/SIDA. Conclusión: Las adolescentes asentadas están marcadas por la subordinación de género, que a menudo es negada y naturalizada por los ideales de legitimar la desigualdad entre los sexos.

Palabras clave: Inequidad de Género; Salud del Adolescente; Vulnerabilidad; Síndrome de Inmunodeficiencia Adquirida; Enfermedades de Transmisión Sexual.

Fecha de recepción: 01/04/2019

Fecha de aceptación: 04/03/2020 


\section{INTRODUÇÁO}

As Infecçóes Sexualmente Transmissíveis (IST) continuam representando um dos maiores desafios, sobretudo, aos órgãos governamentais e ao campo das investigaçôes científicas e tecnológicas ${ }^{(1)}$. Estimase que mais de um milhão de pessoas adquirem uma IST diariamente, e que a cada ano, 500 milhôes se infectam por uma das IST curáveis ${ }^{(2)}$.

Embora o Brasil seja reconhecido internacionalmente como modelo no manejo das IST, em especial da Síndrome da Imunodeficiência Adquirida (AIDS), altas taxas têm sido reportadas, e o perfil epidemiológico tem sido marcado pela feminização e machismo, com maior proporção de infecçóes entre a populaçáo feminina de baixa renda e na faixa etária de 13 a 19 anos $^{(3)}$.

A maior vulnerabilidade dos adolescentes e adultos jovens às IST/HIV/AIDS, principalmente da população feminina, pode ser determinada por fatores como: precocidade na sexarca, multiplicidade de parcerias sexuais, uso/abuso de álcool e outras drogas e a baixa adesão ao preservativo, associados a uma maior liberdade sexual, instabilidade emocional, falta de informaçóes, iniquidade de gênero, cultura hegemônica de masculinidade, violência baseada no gênero e carência de definiçóes de políticas públicas de saúde eficazes em hebiatria ${ }^{(4-8)}$. Sabe-se que a consulta na adolescência representa importante papel para discutir as iniquidades de gênero, empoderamento sexual e corresponsabilidade na adesão de ambos os sexos às medidas preventivas ${ }^{(8)}$.

Ainda são escassas as investigaçóes voltadas à saúde de pessoas que residem em áreas de assentamento urbano, locais de extrema pobreza, marginalizados e invisíveis pela sociedade e setores governamentais. Os poucos estudos foram conduzidos em assentamentos informais e evidenciaram que comportamentos e atitudes de risco para as IST/HIV/AIDS são mais prevalentes que em áreas tradicionais de moradia ${ }^{(9-13)}$. Nesse sentido as adolescentes assentadas, devido às características dessa fase do desenvolvimento, juntamente com os aspectos inerentes a situaçáo de assentamento possui vulnerabilidade individual, social e programática às infecçôes transmitidas pela via sexual. Nesse contexto, o enfermeiro deve compreender tal fenômeno de forma a prestar cuidado baseado em evidência que minimizem as iniquidades de gênero.

Assim, o presente estudo objetivou compreender a percepçáo acerca da vulnerabilidade às IST/HIV/ AIDS entre adolescentes do sexo feminino de um assentamento urbano de uma capital brasileira, localizada na região central do país. O mérito deste estudo está pautado na atual tendência de aumento na incidência das IST e HIV/AIDS na população jovem, na necessidade em construir conhecimento para fortalecer a consulta de enfermagem em hebiatría, nos estudos incipientes com abordagem relacional de gênero e masculinidade associada às infecçóes de transmissão sexual e a inexistência, no Brasil, de estudos com adolescentes femininas de assentamento urbano, um grupo social emergente e negligenciado pelas atuais políticas de prevenção.

Como no Brasil os assentamentos urbanos são comumente sub-reconhecidos em pesquisas, a ausência de dados contribui para políticas públicas que apontam intervençóes isoladas que raramente abarcam as peculiaridades desse grupo. Embora exista um número abundante de estudos sobre sexualidade e IST/HIV/AIDS em adolescentes, pouquíssimo se sabe sobre as representaçóes sociais de gênero e vulnerabilidade a essas infecçóes em adolescentes de assentamentos. Portanto, esta investigação avança na formulação de estratégias de prevenção e controle das IST/HIV/AIDS em hebiatria.

\section{MATERIAL E MÉTODO}

Estudo descritivo e exploratório, de abordagem qualitativa, realizado em um assentamento urbano da periferia de uma capital do Brasil central. Trata-se de um assentamento urbano destinado especialmente a famílias compostas por mulheres provedoras do lar, com filhos e processos familiares interrompidos.

Refletindo-se no contexto da baixíssima adesão a consulta hebiátrica, conforme objeto da investigação de corte transversal ${ }^{(11)}$, que buscamos apreender e analisar as representaçôes sociais construídas pelas adolescentes, tendo como matriz, a teoria das representaçóes sociais ${ }^{(14)}$.

Todas as adolescentes assentadas foram convidadas a participar do estudo, sendo que a seleção procedeu-se por meio de amostragem 
por conveniência e o número de participantes foi determinado pelo princípio da pesquisa qualitativa, que ocorre com a saturação dos dados.

Foram elegíveis indivíduos do sexo feminino na faixa etária de 12 a 18 anos, matriculadas na única instituição de ensino e residentes do assentamento há pelo menos 12 meses e que participaram do estudo prévio ${ }^{(11)}$. Não foram sujeitos da presente pesquisa as adolescentes que náo haviam iniciado prática sexual. Deste modo, a investigaçáo contou com a participação de 16 adolescentes escolares com faixa etária de 12 a 17 anos (Figura 1).

A coleta de dados realizou-se por meio de entrevistas gravadas em gravador digital, previamente autorizado para obtenção de informaçôes fidedignas e completas. Os relatos foram obtidos a partir da seguinte questáo norteadora: "Fale-me a respeito de sua sexualidade e vulnerabilidade às IST/HIV/ AIDS”. As entrevistas foram realizadas no mês de agosto de 2017 em ambiente fechado na unidade de saúde do assentamento, sendo posteriormente transcritas na íntegra.

O processo analítico das narrativas das adolescentes investigadas deu-se pela modalidade temática de $\operatorname{Bardin}^{(15)}$, que consiste em um conjunto de técnicas de análise das comunicaçóes, por meio de procedimentos sistemáticos e objetivos de descrição do conteúdo das mensagens.

A metodologia de análise de conteúdo avalia as falas coletadas, objetivando a identificação do que está sendo dito a respeito de determinado tema, sendo percorridas as etapas de pré-análise (organiza o material, sistematizando as ideias iniciais); exploração do material (definição de categorias e unidade de significação) e tratamento dos resultados, inferência e interpretação ${ }^{(15)}$.

O processo de codificação dos dados obtidos resultou nas categorias temáticas apresentadas nesse artigo: I) Sentimento de invulnerabilidade às IST/ HIV/AIDS; II) Relação de gênero e vulnerabilidade às IST/HIV/AIDS e III) Sexualidade, rede social e vulnerabilidade às IST/HIV/AIDS.

A pesquisa foi aprovada pelo Comitê de Ética em Pesquisa da Universidade Federal de Goiás (protocolo no 365/11). Após interesse em participar da coleta de dados foi entregue o Termo de Assentimento e Consentimento Livre e Esclarecido, assinado por elas e pelos pais e/ou responsáveis legais. A fim de garantir o sigilo e o anonimato dos sujeitos da pesquisa, as falas foram identificadas com o pseudônimo "voz", acrescido por número arábico, de acordo com a ordem das entrevistas realizadas.

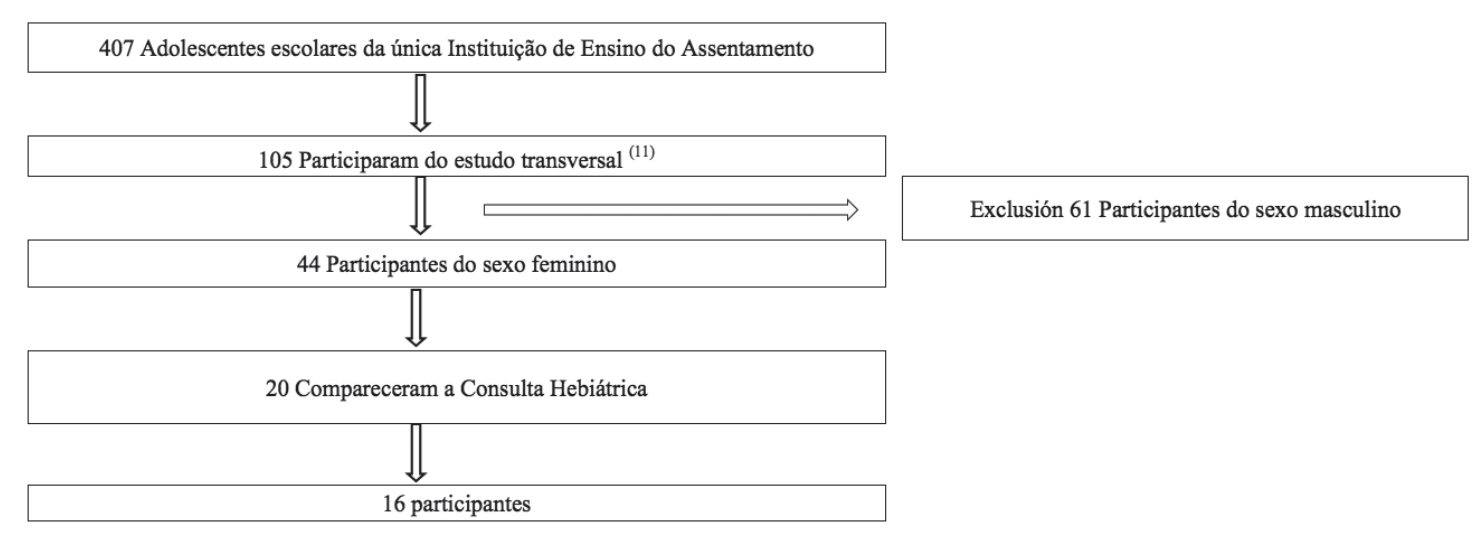

Figura 1: Fluxograma de seleção da amostra do estudo.

\section{RESULTADOS}

Do total de adolescentes investigadas, a faixa etária variou de 12 a 17 anos (mediana 14,5), sendo que todas residiam no assentamento há mais de dois anos (média de 37 meses).
I) Sentimento de invulnerabilidade às IST/HIV/ AIDS. Mesmo diante do consenso na literatura quanto à vulnerabilidade biológica e social da mulher às IST/HIV/AIDS, os avanços nos padróes relacionados à discussão da sexualidade humana ainda são incipientes. Existe disponibilidade e 
amplo acesso as inúmeras fontes e estratégias de informaçốes e incentivo a políticas públicas de saúde sexual e reprodutiva em várias esferas do ciclo de vida da população feminina ${ }^{(1,4,8)}$, no entanto, muitas adolescentes assentadas ainda se percebem invulneráveis às infecçôes transmitidas via sexual. As falas demonstram:

“...acho o homem mais vulnerável. Não sei por quê! ...eu já namoro faz seis meses, ai tipo, náo preciso mais usar camisinha, mas eu tomo remédio pra não engravidar" (Voz 03).

“... a única pessoa que eu fiz aquilo, transar sem camisinha, foi com o meu namorado, com quem eu perdi a virgindade e nunca mais. Agora tomo anticoncepcional e faço preventivo todo ano. Tenho que me cuidar!" (Voz 12).

Diante o contexto de percepção equivocada, emerge a necessidade de fomentarmos junto as adolescentes do assentamento urbano, estratégias de ação-reflexão acerca de seu limiar de vulnerabilidade, empoderamento e corresponsabilidade, haja vista que indivíduos que não se sentem vulneráveis a determinado agravo não costumam aderir às medidas preventivas ${ }^{(7)}$.

O fato de apenas vinte adolescentes assentadas que participaram do estudo quantitativo ${ }^{(11)}$ terem comparecido à consulta hebiátrica, reforça a percepção de invulnerabilidade às IST/HIV/ AIDS. A totalidade das assentadas relatou que não compareceu a unidade de saúde devido à falta de tempo, sendo que a equipe do estudo permaneceu intensivamente, por dois meses, na Unidade Básica de Saúde do assentamento, inclusive realizando busca ativa, divulgação na instituição de ensino e na Organização da Sociedade Civil do assentamento, bem como conseguindo liberação da escola para participação na consulta.

Ainda, na presente investigação, as adolescentes se sentem invulneráveis às IST/HIV/AIDS, delegam a posição de decisão de assentir medidas preventivas aos seus parceiros, porém não compartilham a responsabilidade das consequências de uma sexualidade não saudável (IST e gravidez indesejada) as suas parcerias do sexo masculino:

"Se eu ficar grávida meu pai fica doido.... Agora DST eu vou tratar e náo conto pra ninguém! " (Voz 14).

"Se eu ficar grávida eu que tenho que cuidar, minha vó já falou. Mas acho que ela me ajuda! ”(Voz 07).
Também, parece unânime nos discursos das assentadas a relação de subalternidade de gênero no âmbito familiar, sendo necessária a construção de uma estrutura social fundamentada no diálogo e na relação de poder.

\section{II) Relação de gênero e vulnerabilidade às} IST/HIV/AIDS. Embora mulheres e homens tenham sua igualdade formal reconhecida em todos os aspectos, desde os primórdios as mulheres enfrentam lutas para apagar o quadro cultural de subordinação e submissão ao qual estão historicamente inseridas ${ }^{(16)}$. Muitas foram às conquistas, mas existem ainda muitas questóes no contexto da sexualidade humana vivenciadas com dificuldade pelo sexo feminino, de forma singular pelas adolescentes $^{(17)}$.

As relaçóes de desigualdade entre os sexos, permeadas pelas construçóes culturais estereotipadas de dominação, inferioridade e descaso com as mulheres, favorece e naturaliza as desigualdades de poder nas relaçôes, que por sua vez, negam à mulher o direito de exercer sua sexualidade plena e explorar o prazer sexual ${ }^{(17,18,19)}$. A hegemonia masculina nas relaçóes interpessoais é descrita a continuação:

"Na relação o homem que tem que mandar porque ele que se sente atraido pela mulher neh!" (Voz 15).

"Eu acho que é o homem que manda... Sei lá. É assim" (Voz 05).

"Então ele tem que mandar e a mulher como se diz, ela tem que obedecer para o homem se sentir melhor. Como diz o ditado: dar mais prazer. A relação dá mais prazer então o homem tem que se sentir mais poderoso" (Voz 02).

Tal processo sustenta a manutenção das desigualdades, induzindo a sociedade a enxergar o papel social atribuído às mulheres de inferioridade e subordinação em relação aos homens ${ }^{(19)}$. Como visto nos relatos, muitas mulheres possuem dificuldade em desenvolver sua autoconfiança, caracterizando sua sexualidade como algo silencioso, já que o prazer masculino é tido como prioridade.

Diante as representaçôes sociais de submissão das mulheres descrito acima, somado a sua responsabilização pelas questóes reprodutivas (contracepção e concepção) e imaturidade inerente a adolescência, o diálogo com seus parceiros acerca de medidas preventivas representa um grande desafio $^{(8,10,19)}$. A despeito da negociação do uso 
do preservativo masculino, verifica-se novamente a hegemonia masculina e a submissáo à vontade do parceiro, quando questionadas sobre o uso do preservativo e a insistência diante da recusa:

"Às vezes...mas não insisto. Ele vai pensar que estou traindo ele ou falando que ele tá me traindo..." (Voz 04).

"Quando ele pede para eu não usar a camisinha eu não uso..." (Voz 10).

Percebe-se que as adolescentes elucidaram o grau de subordinação ao desejo masculino, se apresentando submissas à vontade do parceiro e, por conseguinte, cedendo a comportamentos/ atitudes de risco às IST/HIV/AIDS.

Nesse sentido, não é possível delinear políticas de prevenção sem levar em consideração as relaçôes de gênero enquanto relaçóes de poder, sensibilizando os homens a corresponsabilizar pela sua saúde e de sua parceria.

III) Sexualidade, rede social e vulnerabilidade às IST/HIV/AIDS. $\mathrm{O}$ universo da adolescência deve ser analisado de forma a se considerar, conjuntamente, as múltiplas facetas, na qual a rede social: família, amigos, serviços de saúde, mídia e escola, são fundamentais para o processo de adolescer. Essa é uma questão extremamente relevante quando se faz referência a sexualidade, já que as percepçóes das adolescentes são formuladas justamente a partir de suas diversificadas experiências cotidianas e valores construídos ao longo de sua própria trajetória de vida ${ }^{(5-8,12,16)}$.

Uma participante do estudo destaca aspectos relacionados a esse ponto:

"Eu acho que cabe a todos... Os pais têm que orientar o filho né! Na escola o professor também ajuda né! e na saúde sempre é bom tá orientando melhor pra abrir mais a cabeça do adolescente..." (Voz 06).

Segundo as representaçóes sociais das assentadas, seus pais apresentam limitaçóes em abordar o tema, como podemos verificar pelas falas:

"Na verdade meus pais nunca falaram isso comigo não. Nunca!" (Voz 16). "Eles já falaram só de Aids mais não entendi, não quis ficar perguntando..." (Voz 08).

“.... Ah, deveria ser os pais falarem. Mas minha mãe também não me dá muita moral não e eu não moro com meu pai..." (Voz 11).
Em relação à rede social escola, um importante equipamento social, aparece nos relatos como uma instituição que ainda apresenta dificuldade em debater sexualidade em seus programas de ensino, como pode ver a seguir:

"Já falou na escola de camisinha, mas não sei como funciona. Não falam direito, ai fico com vergonha de perguntar, mas eu queria saber..."(Voz 01).

Os adolescentes têm muita curiosidade acerca da sexualidade e carecem que esse ambiente escolar preencha esta lacuna, já que ela detém o importante papel de fomentar o pensamento crítico reflexivo, o convívio com a diversidade e a participação coletiva entre os adolescentes e a comunidade na qual estão inseridos ${ }^{(5,12,16)}$. Faz-se premente, a formulaçáo, gestão e controle social das políticas públicas existentes, e por hora, ainda não aplicadas de forma efetiva nos assentamentos.

Quando a temática norteou para o esclarecimento acerca do acesso as informaçóes e busca de atendimento à saúde para a realização de medidas preventivas, observou-se nas representaçóes das adolescentes, que os profissionais da saúde também vivenciam dificuldades em aproximar-se do tema, como podemos notar nas falas:

"Os profissionais de saúde que deviam falar de sexo. Acha que é melhor eles explicarem pra gente. Mas eles não explicam geralmente né! "(Voz 13).

"Já fui no posto. Na verdade, eles nunca falaram sobre sexo comigo não..." (Voz 09).

A atuação da instituição de saúde parece estar distante da realidade das adolescentes, fator que contribui, sobremaneira, para a vulnerabilidade dessas adolescentes às infecçóes de transmissão sexual e sexualidade distorcida, sendo imperativas discussóes concretas sobre esta problemática, considerando a responsabilidade ético-legal dos profissionais de saúde, bem como os anseios desse grupo.

\section{DISCUSSÃO}

As mulheres em geral, devido a questóes biológicas, como a extensa exposiçáo da mucosa vaginal ao sêmen, cavidade genital sensível a traumas e a maior concentração do HIV no líquido seminal, somado as questôes sociais de relação desigual de poder 
entre os gêneros, são notadamente vulneráveis às IST/HIV/AIDS $^{(1,2,20,21)}$. Quanto as adolescentes, a vulnerabilidade tem si mostrado ainda maior, uma vez que o adolescer é uma etapa do ciclo vital marcada pela imaturidade biopsicossocial, cultural e espiritual, na qual os comportamentos de risco são frequentes, e geralmente subestimados ${ }^{(16,22)}$.

Em relação à percepção de vulnerabilidade, um estudo transversal com uma população de mais de 1000 mulheres, encontrou que cerca de dois terços de sua amostra acreditavam que era impossível ou quase impossível adquirir uma Infecção Sexualmente Transmissível ${ }^{(4)}$. Outros estudos conduzidos com diferentes grupos de adolescentes também demonstraram as representaçóes sociais de se sentirem invulneráveis às IST/HIV/AIDS $(7,8,10,17)$.

Mesmo com a produção de conhecimento ainda incipiente em populaçóes de assentamento urbano, as práticas de subalternidade feminina, que muitas vezes é negada e naturalizada pelos ideais de legitimação de desigualdade entre os sexos são mais expressivas nesse segmento populacional ${ }^{(13)}$. Esse achado abrange também outros grupos de mulheres, em particular as populaçóes marginalizadas, como as mulheres rurais, moradores de rua, catadoras de materiais recicláveis, entre outras ${ }^{(2)}$.

Estudo com indivíduos do sexo masculino de um assentamento evidenciou que os homens consideram que o seu risco em adquirir uma infecção transmitida por via sexual está associado aos comportamentos de suas parcerias sexuais femininas, e náo decorrente de seus próprios comportamentos/atitudes de risco ${ }^{(18)}$. Esses resultados evidenciam que, tanto os adolescentes de assentamento urbano homens, quanto às mulheres, possuem um comportamento de transferência de responsabilidade, muito provavelmente relacionado à sua imaturidade, própria dessa fase da vida, ancorados na iniquidade de gênero.

Não obstante, esse fenômeno deve ser discutido por toda a rede social das adolescentes, em particular pelos profissionais de saúde, uma vez que há uma percepção equivocada e machista de papéis, à medida que é transmitida as adolescentes os encargos decorrentes da saúde sexual e reprodutiva, e por sua vez, essas adolescentes, geralmente, de forma passiva assumem tal atribuição, resguardando os adolescentes homens de suas responsabilidades.

Segundo as Naçóes Unidas sobre HIV/AIDS
(UNAIDS), os casais, em sua maioria, apresentam dificuldades em negociar o uso do preservativo masculino ${ }^{(20)}$. Nesse estudo, as adolescentes não conseguem negociar o uso do método de barreira, já que a simples discussáo é motivo para colocar em dúvida sua fidelidade, gerando medo do abandono. Ainda, à mulher é tolhido o direito de portar o preservativo consigo, mantendo-se calada para não provocar desconfiança do parceiro. Esse achado corrobora inúmeros estudos com diferentes grupos populacionais $^{(8,10,19,20,23)}$.

Enquanto esse contexto de desigualdade de gênero permanecer, é importante ressaltar que a população masculina deve ser alvo de estratégias maciças de prevenção e conscientização, uma vez que a decisão do uso de métodos de barreira é muitas vezes delegada ao homem ${ }^{(8)}$.

Não obstante, mesmo com a real demanda das adolescentes, vulnerabilidades inerentes à adolescência, a situação de assentamentos, e as atuais políticas inter setoriais de incentivo ao diálogo acerca da sexualidade e às IST/HIV/AIDS, discutir a temática ainda representa um desafio para toda a rede social das adolescentes. Todavia, são imprescindíveis políticas inter setoriais que se voltem aos temas da sexualidade, haja vista as evidências que a articulação da família, escola e profissionais de saúde, representa um fator protetor da sexualidade da adolescente, particularmente enfocando aspectos relativos à iniquidade de gênero $^{(6,7,24)}$.

O comportamento parental, em particular o diálogo, tem sido um preditor significativo nas atitudes e comportamentos sexuais saudáveis dos adolescentes. Todavia, nota-se que a sexualidade ainda é tratada como tabu nas famílias e, na maioria das vezes, a adolescente não consegue conversar com seus pais sobre comportamentos sexuais. Autores reportam que para os pais levantarem esse tema também se configura numa experiência extremamente conflituosa, pois muitas vezes, tiveram a formaçáo da sexualidade repleta de mitos e tabus que contribuíram para compreensóes distorcidas, que prejudica sobremaneira a sua própria vivência sexual, e, por conseguinte, de suas filhas ${ }^{(5,6,8,18)}$.

Diante esse contexto, as famílias têm delegado essa atribuição às instituiçóes de ensino, que por sua vez também não estão preparadas pedagogicamente para exercerem de forma assertiva tal atribuição. 
Acredita-se que o Programa Saúde na Escola (PSE), instituído no Brasil em 2007, representa uma estratégia inovadora para o fortalecimento das açóes de promoção da saúde da população feminina do país, proporcionando credulidade aos questionamentos das adolescentes e ao papel social transformador desempenhado pela escola. Todavia, mesmo sendo um programa governamental, os adolescentes do assentamento em estudo não possuem este programa implantado na sua instituição de ensino, muito provavelmente em detrimento da invisibilidade desses indivíduos que vivem às margens dos grandes centros, ratificando a insistência dos gestores públicos em não assumirem sua responsabilidade no processo educativo das adolescentes.

A dificuldade de pais e educadores em tratar do tema sexualidade possivelmente reside no fato de acreditarem que, uma vez mantidos diálogos acerca de tal temática, poderiam estar incentivando as adolescentes à prática sexual, fato já identificado por outros autores ${ }^{(5,18,19)}$. Ainda, para tratar de forma aberta o tema em questão, faz-se necessário, a princípio, trabalhar adequadamente a sexualidade individual de cada um, uma vez que geralmente a educação voltada para a sexualidade também foi recebida pelos pais carregada de preconceitos e tabus. Depreende-se daí que a omissão dos profissionais do setor educacional, neste caso, potencializa a vulnerabilidade social e em saúde das adolescentes, indicando lacunas no plano programático do sistema de ensino e a falta de açóes preventivas $^{(7,9,25)}$.

Nas instituiçóes de saúde as açóes educativas no campo da saúde sexual e reprodutiva, por meio de estratégias com evidência científica, contribui para que a adolescente reflita sobre sua real condição de vulnerabilidade, contemplando um novo olhar em relação à desigualdade entre os sexos, com vistas à autonomia sexual com incorporação de atitudes saudáveis.

Nesse sentido, torna-se imperioso discutir e repensar a atuação dos profissionais de saúde junto a essa população, uma vez que o profissional, quando ciente das necessidades do público alvo de suas açóes, poderá direcionar seu cuidado para uma assistência integral e, que de fato, seja transformadora da realidade local.

Relevante estudo evidenciou que intervençôes em assentamentos são capazes de reduzir os comportamentos de risco para as IST/HIV/AIDS e contribui para a construção coletiva de uma sexualidade saudável, na qual há equidade de gênero e respeito às diferençass ${ }^{(26)}$.

É importante reforçar que, de fato, as representaçóes sociais levantadas pelas adolescentes assentadas ratificam que a problemática da iniquidade de gênero é potencialmente passível de mudança, sendo necessário um esforço articulado para a formação de estratégias que promovam a integração entre pais, educadores, profissionais da saúde e comunidade.

Acredita-se que a presente investigação trouxe uma contribuição pioneira para a enfermagem, já que o estudo levantou evidências que subsidiam um cuidado dirigido com um novo olhar para a hebiatria. Diante o exposto, o profissional na consulta de enfermagem e nas atividades preventivas e protetivas, devem considerar as iniquidades de gênero e invulnerabilidade para propor intervençóes que suplantam os preconceitos, e consequentemente possibilite um assistir mais humanizado, holístico e resolutivo. Frente a essa consciência, as instituições educadoras do assentamento, juntamente com outros equipamentos sociais existentes, configuramse como espaços favoráveis para a realização de programas educativos que visem à promoção da saúde sexual e reprodutiva saudável e a percepção de vulnerabilidade às doenças transmitidas por via sexual. Essas estratégias devem ocorrer por meio não só do trabalho de educação em saúde com o público adolescente, como também pela educação continuada, com vistas a instrumentalizar os profissionais da saúde e educação.

As intervençóes propostas devem ser articuladas às redes sociais da adolescente (família, amigos, professores e pais), resguardando as diferenças nas necessidades das adolescentes femininas, baseadas na equidade, integralidade e humanização, livres de ideias e estereótipos. Ainda, faz-se necessário consolidar os profissionais de saúde não só como atuantes diretos no tratamento das infecçôes, mas como educadores a respeito das boas práticas de saúde, com um olhar holístico e individualizado que promova a qualidade de vida, com igualdade de gênero, da coletividade.

Embora o estudo apresente ineditismo e avanços para a saúde do adolescente, apresenta, evidentemente, limitaçóes, pois os achados não são generalizados, pressupostos de investigaçóes 
qualitativas. Ainda, as falas podem sofre alteraçóes devido ao viés de memória e o receio frente à pergunta norteadora. A despeito dessas limitaçóes, o estudo permitiu verificar a compreensão de sexualidade induzida e invulnerabilidade às IST/ HIV/AIDS das adolescentes assentadas.

\section{CONCLUSÃO}

A adolescência, como etapa entre o ser criança e o ser adulto, é o período fundamental de formação da identidade sexual e da cultura em torno da sexualidade, por isso a importância de identificar quais as percepçóes que essa população tem acerca da sexualidade e vulnerabilidade às IST/HIV/ AIDS.

Respeito de a sexualidade e vulnerabilidade às IST/HIV/AIDS de adolescentes deste estudo, emergiram as seguintes categorias temáticas: Sentimento de invulnerabilidade às IST/HIV/

\section{REFERÊNCIAS}

1. World Health Organization. Progress report on HIV, viral hepatitis and sexually transmitted infections 2019 [Internet]. 2019 [citado 2020 feb 24]; 48p. Disponível em: https://apps.who.int/iris/ bitstream/handle/10665/324797/WHO-CDSHIV-19.7-eng.pdf

2. World Health Organization. Report on global sexually transmitted infection surveillance 2018 [Internet]. 2018 [citado 2020 abr 26]; 63p. https:// www.who.int/reproductivehealth/publications/ stis-surveillance-2018/en/

3. Ministério da Saúde - Secretaria de Vigilância em Saúde - Departamento de DST. Aids e Hepatites Virais. Boletim Epidemiológico HIV/Aids. Brasília (DF): Ministério da Saúde; 2019. 72 p.

4. Mesenburg MA, Muniz LC, Silveira MF. Assessment of sexual risk behaviors and perception of vulnerability to sexually transmitted diseases/ acquired immunodeficiency syndrome in women, 1999-2012: a population based survey in a medium-sized Brazilian city. Braz J Infect Dis. [Internet] 2014 ago [cited 2020 July 16]; 18(4): 414-420. Disponível em: http://www.scielo. br/scielo.php?script=sci_arttext\&pid=S141386702014000400414\&lng=en.

5. Unemo M, Bradshaw CS, Hocking JS, Henry JC, Francis SC, Mabey D, et al. Sexually transmitted
AIDS, relação de gênero e vulnerabilidade às IST/HIV/AIDS e Sexualidade, rede social e vulnerabilidade às IST/HIV/AIDS. Nos relatos foi possível perceber as crenças, mitos, preconceitos e tabus que persistem no âmbito da sexualidade e como a conjuntura social influencia para permanência dessa condição.

Assim, as adolescentes assentadas são marcadas pela subalternidade de gênero, que muitas vezes é negada e naturalizada pelos ideais de legitimação de desigualdade entre os sexos. As relaçóes de sexo desiguais parecem ser um dos fatores que mais prejudicam o desenvolvimento de uma sexualidade saudável, corroborando para a percepção de invulnerabilidade às IST/HIV/AIDS das adolescentes investigadas.

Por fim, a carência de estudos nacionais e internacionais abre espaço para outros estudos com essa população, bem como outras mulheres vítimas das iniquidades de gênero.

infections: challenges ahead. Lancet Infect Dis. [Internet] 2017 ago [citado 2020 jun 16]; 17(8): e235-e279. Disponível em: http://dx.doi. org/10.1016/ S1473-3099(17)30310-9

6. Hong E, Kang Y. Gender Differences in Sexual Behaviors in Korean Adolescents. Journal of Pediatric Nursing. [Internet] 2017 ago [citado 2020 jun 16]; 37: e16-e21. Disponível em: https:// doi.org/10.1016/j.pedn.2017.08.020

7. Pederson A, Greaves L, Poole N. Gendertransformative health promotion for women: a framework for action. Health Promot Int. [Internet] 2015 sep [citado 2020 jun 16]; 30(1): 140-50. Disponível em: https://doi.org/10.1093/heapro/ dau083

8. Muchomba FM, Chan C, El-Bassel N. Importance of Women's Relative Socioeconomic Status within Sexual Relationships in Communication about Safer Sex and HIV/STI Prevention. J Urban Health. [Internet] 2015 feb [citado 2020 jun 16]; 92(3): 559-71. Disponível em: https://doi.org/10.1007/ s11524-014-9935-y

9. Lee, Regina Lai Tong et al. A systematic review on identifying risk factors associated with early sexual debut and coerced sex among adolescents and young people in communities. Journal of clinical nursing. [Internet] 2018 jun [citado 2020 jun 16]; 27(3-4): 478-501. Disponível em: https://doi. org/10.1111/jocn. 13933 
10. Andrade SSC, Zaccara AAL, Leite KNS, Brito KKG, Soares MJGO, Costa MML, et al. Knowledge, attitude and practice of condom use by women of an impoverished urban area. Rev esc enferm USP. [Internet] $2015 \mathrm{feb}$ [citado 2020 jun 16]; 49(3): 364-371. Disponível em: https://doi. org/10.1590/S0080-623420150000300002.

11. Santos-Carvalho PM, Guimaráes RA, Moraes PA, Teles S, Matos MA. Prevalência de sinais e sintomas e conhecimento sobre doenças sexualmente transmissíveis. Acta Paul Enferm. [Internet] 2015 [citado 2020 jun 16]; 28(1): 95. Disponível em: https://doi.org/10.1590/1982-0194201500016.

12. Kaufman ZA, Braunschweig EN, Feeney J, Dringus S, Weiss H, Delany-Moretlwe S, et al. Sexual risk behavior, alcohol use, and social media use among secondary school students in informal settlements in Cape Town and Port Elizabeth, South Africa. AIDS and behavior. [Internet] 2014 jun [citado 2020 jun 16]; 18(9): 1661-1674. Disponível em: https://doi.org/10.1007/s10461-014-0816-x

13. Guimarães RA, Souza MMD, Caetano KAA, Teles SA, Matos MA et al. Use of illicit drugs by adolescents and young adults of an urban settlement in Brazil. Rev Assoc Méd Bras. [Internet] $2018 \mathrm{feb}$ [2020 jun 16]; 64(2): 114-118. Disponível em: https://doi.org/10.1590/1806-9282.64.02.114.

14. Moscovici, S. Representaçôes sociais: investigaçôes em psicologia social. 11 ${ }^{\mathrm{a}} \mathrm{ed}$. Rio de Janeiro: Vozes; 2011. $404 \mathrm{p}$.

15. Bardin L. Análise de conteúdo. 6a ed. Lisboa: Edições 70; 2011. 229 p.

16. Patton GC, Sawyer SM, Santelli JS, Ross DA, Afifi R, Allen NB et al. Our future: a Lancet commission on adolescent health and wellbeing. The Lancet. [Internet] 2016 [citado 2020 jun 16]; 387(10036): 2423-2478. Disponível em: https:// doi.org/10.1016/S0140-6736(16)00579-1

17. Torrone, Elizabeth A. et al. Prevalence of sexually transmitted infections and bacterial vaginosis among women in sub-Saharan Africa: An individual participant data meta-analysis of 18 HIV prevention studies. PLoS medicine. [Internet] 2018 [citado 2020 jun 16]; 15(2): e1002511. Disponível em: https://doi.org/10.1371/journal. pmed.1002511

18. Arraes CDO, Palos MAP, Barbosa MA, Teles SA, Souza MMD, Matos MAD. Masculinity, vulnerability and prevention of STD/HIV/AIDS among male adolescents: social representations in a land reform settlement. Rev Latino-Am Enfermagem. [Internet] 2013 oct [citado 2020 jun 16]; 21(6): 1266-1273. Disponível em: http:// dx.doi.org/10.1590/0104-1169.3059.2363.

19. Couto MT, Dantas SM. Gender, masculinities, and health in review: production of the field in the journal Saúde e Sociedade. Saúde e Sociedade. [Internet] 2016 oct [citado 2020 jun 16]; 25(4): 857-868. Disponível em: https://doi.org/10.1590/ S0104-12902016172308

20. UNAIDS Brasil. UNFPA, OMS e UNAIDS: Declaração de posição sobre preservativos e a prevenção do HIV, outras infecçóes sexualmente transmissíveis e gravidez indesejada. Brasília: UNAIDS Brasil. [Internet] 2015 [citado $2017 \mathrm{abr}$ 15]. Disponível em: http://unaids.org.br/2015/07/ unfpa-oms-e-unaids-declaracao-de-posicaosobre-preservativose-a-prevencao-do-hiv-outrasinfeccoes-sexualmente-transmissiveis-e-gravidezindesejada/.

21. Chivers ML. The specificity of women's sexual response and its relationship with sexual orientations: A review and ten hypotheses. Arch Sex Behav. [Internet] 2017 jan [citado 2020 jun 16]; 46(5): 1161-1179. Disponível em: https://doi. org/10.1007/s10508-016-0897-x

22. Erenoglu R, Sekerci YG. The Effect of Training Program Given to The Students upon Family Planning Attitudes; A Semi-Experimental Study. Cukurova Medical Journal. [Internet] 2020 [citado 2020 jun 16]; 45(3), 1-1. Disponível em: https:// doi.org/10.17826/cumj.000000

23. Obembe TA, Adebowale AS, Odebunmi KO. Perceived confidence to use female condoms among students in Tertiary Institutions of a Metropolitan City, Southwestern, Nigeria. BMC research notes. [Internet] 2017 ago [citado 2020 jun 16]; 10(1): 398. Disponível em: https://doi.org/10.1186/ s13104-017-2730-6

24. Abuya BA, Elungata P, Mutisya M, Kabiru CW. Parental education and high school completion in the urban informal settlements in Kenya. Cogent Education. [Internet] 2017 [citado 2020 jun 16]; 4(1): 1369489. Disponível em: https://doi. org/10.1080/2331186X.2017.1369489

25. Sidze EM, Elungata'a P, Maina BW, Mutua MM. Does the Quality of Parent-Child Connectedness Matter for Adolescents' Sexual Behaviors in Nairobi Informal Settlements? Arch Sex Behav. [Internet] 2015 dic [citado 2020 jun 16]; 44(3): 631-638. Disponível em: https://doi.org/10.1007/s10508014-0402-3

26. Wanje G, Masese L, Avuvika E, Baghazal A, Omoni G, McClelland RS et al. Parents' and teachers' views on sexual health education and screening for sexually transmitted infections among inschool adolescent girls in Kenya: a qualitative study. Reproductive health. [Internet] 2017 ago [citado 2020 jun 16]; 14(1): 95. Disponível em: https://doi.org/10.1186/s12978-017-0360-z 